\title{
Nacionalismo e autoritarismo em Alberto Torres
}

RICARDO LUIZ DE SOUZA

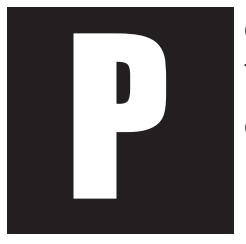

oucos autores brasileiros encarnam tão bem quanto Alberto Torres a idéia de transição, de fim de um ciclo e início de outro. Em termos políticos, por exemplo, tomemos como ponto de partida a análise que Saldanha faz do impacto provocado por ele e por seus seguidores: "Com eles se encerrou o ciclo do liberalismo oitocentista brasileiro, que pareceu condenado pelo próprio fato de se haver identificado com as soluções constitucionalistas da Primeira República (Saldanha, 1979, vol. I, p. 186)”. E Monzani define Torres como representante de "um pensamento ou ideário autoritário-conservador", e o descreve: "Para esse pensamento não se tratará, é claro, de propugnar a volta pura e simples do regime monárquico, mas sim de pensar a República forte, que escapasse exatamente destas tão flagrantes deficiências da República liberal (Monzani, 1999, p.543)".

Este é o ponto de partida: a definição de Torres como um autor que assinala a transição do predomínio de idéias liberais para a articulação de um ideário republicano que nascia em contraste com a ideologia liberal ainda vigente durante a República Velha, consolidando-se como pensamento dominante apenas a partir dos anos 30. Parto daí para formular a linha argumentativa que pretendo desenvolver: qual a importância de Torres na 
formulação do pensamento autoritário brasileiro, e qual sua importância na elaboração teórica de uma vertente nacionalista que teria larga fortuna na cultura brasileira do século XX? E ainda, a partir de tal linha é possível a formulação de questões que não apenas ajudam a situar o autor em sua época, mas esclarecem o sentido da influência por ele exercida: quais os fundamentos de sua crítica ao liberalismo, qual o sentido de seu nacionalismo, e como ele o tomou como pressuposto para a construção de todo um projeto para a nação? E ainda, como é possível relacionarmos os delineamentos básicos de sua obra com a sua atividade enquanto político e, principalmente, com as frustrações dela decorrentes? São estas as questões fundamentais que buscarei responder ao longo do texto.

A crítica do autor à estrutura política brasileira nasce de desilusões vivenciadas no cotidiano da atividade política. Torres passou da prática à teoria, escrevendo sua obra após ter exercido diversos cargos públicos, entre os quais ministro do STF, ministro do Interior e, entre 1896 e 1900, presidente do Rio de Janeiro. Ali, segundo Felix, o antigo republicano sofre uma cisão em seu pensamento político, desiludindo-se com o regime republicano e constatando a mediocridade vigente na política e na administração brasileira (Felix, 1976, p. 256-269). Seu antiliberalismo, portanto, deriva do contraste por ele percebido entre a prática política e as idéias liberais, tais como vivenciadas nas instituições políticas das quais participou.

Desiludido com a prática política, contudo, Torres não enxerga soluções fora da esfera política e busca transformá-la. Como salienta Costa, referindo-se ao autor:

A solução é, pois, eminentemente política, e a sua forma é necessariamente institucional: o Estado autoritário é o único meio de substituir o "círculo vicioso" da representação dos interesses oligárquicos pelo "círculo virtuoso" da representação dos interesses nacionais (Costa, 1992, p. 221 ). 
Dessa desilusão, portanto, derivou seu antiliberalismo, e Torres foi pioneiro ao transformar a crítica ao liberalismo em base para a construção do pensamento autoritário. De fato, Torres é antiliberal. Para ele, o estado, órgão assegurador da "justiça social", vem suprir as imperfeições do modelo de concorrência espontânea, substituindo a "mão invisível" (Marson, 1989, p. 179). O Estado teria, então, não apenas a função de suprir as deficiências inerentes ao liberalismo como, também, evitar que tais deficiências funcionem como justificativa para a implantação do socialismo. Porque Torres também é anti-socialista.

Dificilmente Torres aceitaria ser rotulado como um pensador autoritário, mas ele, como acentua Florestan Fernandes, estabelece "um confronto entre os critérios formais de reconhecimento da democracia e a realidade política vigente". A conclusão, ainda segundo Fernandes, foi: "as condições reais da vida política brasileira são incompatíveis com o modelo europeu ou norte-americano de organização democrática da ordem legal (Fernandes, 1979, p. 94)". E ele abre, a partir de tal conclusão, um caminho que seria seguido pelo pensadores autoritários brasileiros.

A nação brasileira deveria ser criada pelo Estado. Não caberia a este atuar apenas de forma reguladora, como compete ao Estado em uma nação já desenvolvida, já que o Brasil não criou, ainda, os vínculos orgânicos capazes de consolidarem-no como nação. Não podemos, segundo Torres, darmonos ao luxo de sermos liberais.

Seu antiliberalismo contesta os fundamentos do sistema. Torres nega validade à representatividade baseada no sistema eleitoral e partidário - o que chama de velho constitucionalismo inglês - e propõe substituí-la por uma representação que resulta do acordo íntimo e espontâneo entre as forças da opinião e seus órgãos, e que faz surgir os homens dos sucessos, por influxo dos sentimentos e das necessidades dominantes (Torres, 1982 a 89).

E critica o liberalismo, ainda, por ele ter limitado o âmbito da ação 
estatal, quando deve caber ao Estado - e a um Estado forte - atuar como órgão central de todas as funções sociais, destinado a coordená-las e harmonizá-las - a regê-las - estendendo a sua ação sobre todas as esferas da atividade, como instrumento de proteção, de apoio, de equilíbrio, de cultura (Torres, 1982a, p. 173). A relação da sociedade para com o Estado, portanto, é de dependência: ela depende da ação estatal para organizar-se, superar seus conflitos e deficiências, enquanto o Estado, para Torres, é um espaço desvinculado de interesses e conflitos de poder.

Cabe ao Estado formar o povo, e o que ele chama de democracia política é incapaz de levar adiante tal tarefa, devendo ser substituída por outro tipo de regime:

A democracia social, sucedendo à democracia política, substitui-se o encargo falaz de formar e apoiar o "cidadão" - tipo clássico do titular dos direitos políticos pelo encargo de formar e apoiar o "homem", o "indivíduo", o socius da nação contemporânea. Formar o homem nacional é o primeiro dever do Estado moderno (Torres, 1982a, p. 229).

A democracia social pretendida pelo autor só pode ser concretizada, contudo, por meio de um regime forte, e o elogio desse regime permeia toda a obra do autor: a democracia só pode ser alcançada por meio do autoritarismo e, diga-se de passagem, todos os regimes autoritários brasileiros tiveram, como objetivo declarado, a construção, preservação ou restauração da democracia. O elogio da autoridade está presente, por exemplo, em sua crítica do parlamentarismo e elogio do presidencialismo. Segundo Torres

O parlamentarismo é a antítese da organização, e do governo consciente e forte; é o regime da dispersão, da vacilação, da crise permanente...O Brasil carece de um governo consciente e forte, seguro de seus fins, dono de sua vontade, enérgico e sem contraste. Este governo só o regime presidencial Ihe pode dar (Torres, 1982a, 


\section{p. 247).}

O pensamento de Torres toma como fundamento um evolucionismo de fundo marcadamente positivista no qual o Estado surge como solução e como caminho para um futuro definido pela racionalidade. Trata-se, para ele, de

Fundar o Estado, como órgão da vida social das nações, e fundar o órgão mundial de equilíbrio entre as nações, para, encerrando-se de vez o ciclo da evolução humana que veio, até ao presente, dirigido pelos impulsos da emotividade, encetar-se a evolução das sociedades, dirigida pelo sentimento e pela razão (Torres, 1915, p. 40).

Cabe ao Estado, em síntese, construir a nação e aqui eu retomo meu argumento: a importância de Torres na construção do pensamento autoritário brasileiro deriva, entre outros fatores, da primazia por ele conferida ao Estado sobre a sociedade civil e à tarefa a ele confiada de construção de uma nacionalidade que, por si só, permaneceria dispersa e inorgânica. Seriam argumentos fundamentais, por exemplo, nas obras de Oliveira Viana e Azevedo Amaral, e a influência de Alberto Torres sobre Oliveira Viana é ressaltada por um estudioso da obra deste: A trajetória do pensamento de Oliveira Viana encontra seu ponto de partida, sem dúvida alguma, nas análises de Alberto Torres, cuja problemática está sempre presente, mesmo quando reinterpretada por este (Vieira, 1981, p. 77).

E a hipótese desenvolvida por Torres possui um escopo ainda mais amplo: não apenas o Brasil, mas as nações modernas são, para ele, necessariamente, criações artificiais, e o poder político, nelas, deve atuar de forma autônoma e soberana. Segundo ele,

A autoridade política é, portanto, um poder que se cria a si mesmo, que se impõe e se mantém por sua própria força de móveis opostos às tendências e aos interesses sociais; que dita as normas. E comanda os destinos do 
povo, obedecendo aos instintos de sua origem, ou a idéias arbitrariamente adotadas. Sua ação é predominante e decisiva - soberana em todo o rigor da palavra (Torres, 1941, p. 243-5).

A sociedade, para Torres, é uma entidade amorfa, sem vida interna, e suas energias são todas canalizadas para satisfazer necessidades de caráter individual. É dispersa e inorgânica por definição. Toda a vida de uma nação deriva da ação do que Torres chama de seu aparelho político-administrativo (Torres, 1982a, p. 117), o Estado, portanto. É a política, e apenas ela, que forma a nacionalidade ao subordinar e coordenar os movimentos sociais, e esta é sua função, já que "a vida social, não tendo caráter propriamente orgânico, obedece a uma espécie de harmonia e de equilíbrio, no tempo e no espaço; seus movimentos parciais carecem de subordinação à marcha do todo (Torres, 1982, p. 158)". Sociedade dispersa, amorfa e subordinada; Estado coordenador, autônomo e coeso: reside, nesta dualidade, o fundamento de seu autoritarismo.

Cabe à política, enfim, conferir organicidade à sociedade, e é exatamente esta tarefa que não é levada a cabo no Brasil, gerando, então, uma nação sem união política. Segundo Torres, "nossa união é tão efetiva como a que se vislumbrar, porventura, nas relações de um município do Brasil com um município argentino (Torres, 1982, p. 3)". Mas ele não faz a defesa do centralismo político; pelo contrário, Torres é federalista e justifica sua posição recorrendo à geografia brasileira: "A carta geográfica do Brasil é um imperativo de autonomia provincial (Torres, 1982a, p. 244)".

Ajuda a entendermos suas idéias referentes ao tema, finalmente, o fato de ter ele enviado a Rio Branco, em 1912, um memorial no qual reconhece ser o destinatário o único estadista para o qual ele poderia sugerir medidas que considera indispensáveis à nação e que, em linhas gerais, seriam a nomeação de interventores estaduais por parte do Governo Federal, e a "escolha de uma comissão para o estudo dos problemas sociais e econômicos, para adoção de medidas a serem executadas conjuntamente 
pela União, pelos Estados e pelos municípios (Lins, 1965, p. 430)". Nenhuma dessas medidas foi adotada e, provavelmente, sequer foram cogitadas, mas ajudam a entendermos, ainda, a dimensão da importância atribuída pelo autor à ação estatal.

O pensamento de Torres viria a ser criticado mais tarde, exatamente por seu conteúdo autoritário. Guerreiro Ramos, por exemplo, lembraria que A despeito das observações corretas sobre a sociedade brasileira contidas, à guisa de diagnóstico, em sua obra, incidiu no erro fundamental de pensar que a organização do País pudesse ser outorgada de cima para baixo... O projeto de Alberto Torres só tem valor histórico em nossos dias (Ramos, 1961, p. 86).

E também o fato de Torres haver-se apegado ao estudo da identidade nacional para explicar a realidade brasileira é criticado por ele. Segundo Ramos, Torres errou ao ter "adotado uma concepção psicológica da sociedade, segundo a qual os nossos males poderiam ser erradicados mediante a transformação do caráter nacional", embora ele reconheça, ainda, ter o autor "muitas contribuições a incorporar na formulação de uma sociologia nacional (Ramos, 1957, p. 134)".

Mas, se seu autoritarismo foi alvo de críticas, ele foi, também, a matriz de sua influência. Torres formula a dualidade entre país legal e país real já pressentida, entre outros, por Euclides da Cunha e Sílvio Romero, mas, ao dar a esta expressão a formulação que se tornaria clássica, terminaria por transformá-la em alicerce do pensamento autoritário. E transformaria a mesma em matriz do pensamento conservador, ao associá-la à dualidade entre sociedade urbana e rural, na qual o país legal seria "o país urbano, "sibarita" e cosmopolita, enquanto o país rural é o meio rural, onde jaz o cerne da brasilidade (Melo, 1993, p. 86)".

Também o corporativismo de Torres condiciona o pensamento autoritário brasileiro, e é um dos aspectos de sua obra mais lembrados e elogia- 
dos pelos representantes desta corrente de pensamento. É mencionada em termos elogiosos, por exemplo, em coletânea organizada nos anos vinte, a proposta do autor de substituir os partidos políticos por eleitorados - para assim dizermos - tecnicamente organizados (Nogueira, 1990, p. 94).

Mas sua influência foi além, atuando também sobre movimentos políticos. Neste sentido, Fausto ressalta a convergência entre as propostas de Torres e o ideário tenentista, lembrando ter-se Juarez Távora apoiado expressamente no pensamento deste para redigir seu manifesto de resposta a Prestes em 1930 (Fausto, 1970, p. 68).

E pensarmos a influência exercida por Torres significa dimensioná-la em suas diferentes orientações. A vertente católica do pensamento de Torres permitiria, nos anos 30, por exemplo, que um autor como Tristão de Athayde encontrasse pontos de convergência entre seu pensamento e o de Torres, e os acentuasse. E o próprio autor dá a dimensão da influência alcançada pela obra de Torres nos anos 30, ao afirmar ser ele "de todos os estudiosos de nossos problemas sociais, o mais meditado, o mais compulsado, o mais inquirido como o solucionador da nossa crise e como escultor póstumo, se é lícito dizer, do nosso futuro (Athayde, 1932, p. 179)". Nas palavras de Werneck Vianna, "assim como setores da juventude militar se apropriaram da perspectiva política de Torres, o autoritarismo civil, de inspiração clerical ou jurídica, tomará suas concepções sobre a vida social e econômica como ponto de partida (Vianna, 1978, p. 110)".

A influência de Torres gerou, finalmente, uma corrente de pensamento cujos representantes - Carneiro Leão, Gilberto Amado, Oliveira Viana, entre outros - caracterizam-se, segundo Luz, pelo nacionalismo e pela preocupação com a "organização nacional", ou seja, pela ênfase na necessidade de integrar e assimilar: "integração geográfica pela expansão das vias de comunicação e pelo povoamento dos espaços vazios. Integração étnica através da educação e elevação espiritual (Luz, 1969, p. 73)".

A existência de uma identidade nacional é definida por Torres como 
fundamento para a elaboração de uma política nacional, e esta deve agir como tradução dessa identidade. Segundo ele, "a unidade e a continuidade da política resultam da existência de um caráter nacional (Torres, 1982a, p. $61)^{\prime \prime}$. Por outro lado, onde tal identidade não existe - e é o caso do Brasil cabe ao Estado construí-la, e tal identidade surge, na expressão do autor, como uma obra de arte política. E ele, então, conclui:

Um país só possui integridade e união quando cobre a sua terra, e envolve os seus habitantes, um forte tecido de relações pessoais e interesses práticos; se esses interesses e essas relações não resultam espontaneamente da natureza da terra e do caráter do povo, é indispensável criá-los (Torres, 1982, p. 70).

Crítico incisivo de sua época, Torres é otimista quanto ao futuro e deriva seu otimismo de uma visão favorável do povo brasileiro, e Tavares critica Torres por este não ter conseguido definir as especificidades do povo brasileiro concreto, de seu tempo. Sua obra, pelo contrário, "baseia-se num povo genérico que nunca existiu ou, quando muito, num povo genérico concreto que estava deixando de existir (Tavares, 1979, p. 22)".

Para Torres, de qualquer forma, "somos um dos povos mais sensatos e inteligentes do mundo (Torres, 1982a , p. 55)". E para ele, ainda, "nenhum povo tem melhores estímulos morais e mais alta capacidade moral que o nosso (Torres, 1982, p. 45)". E tal otimismo atinge uma dimensão milenarista, quando ele afirma: "O Brasil é um país destinado a ser o esboço da humanidade futura (Torres, 1982, p. 135)".

Mas se Torres é assim otimista quanto ao futuro, ele é um crítico implacável do passado, e tem uma visão altamente negativa do processo de formação nacional. Republicano histórico, ele critica o monarquismo ao mencionar a ordem imperial, "essa ordem paradisíaca, tão saudosa para alguns", definindo-a como uma ordem baseada no domínio predatório de uma casta e enfeitada pela erudição inútil de doutores e bacharéis. E, em 
relação à colônia, a perspectiva não é menos crítica:

Portugal, enviando para suas colônias os elementos irrequietos do povo sem cultura e sem piedade, assentou as raízes da nossa história econômica sobre a cobiça da riqueza fácil, na mineração e na devastação das matas, com a submissão dos indígenas e a escravização do africano (Torres, 1982, p. 100).

Assim como a identidade nacional, a cultura brasileira, para ele, é coisa que não existe. Segundo ele, "nunca chegamos a construir cultura própria, nem mesmo uma cultura geral... Não temos opinião e não temos direção mental (Torres, 1982a , p. 15 e 16)". E ele acrescenta ainda: "Nós temos ilustração. Não temos cultura (Torres, 1982a, p. 103)". O que ele entende por falta de cultura é a inexistência do que Bourdieu chamaria de campo cultural, ou seja, um conjunto de estabelecimentos educacionais, instituições culturais e um conjunto de intelectuais envolvidos em um permanente processo de debate e concorrência. Falta, exatamente, a elite intelectual que ele reputa indispensável à condução dos destinos nacionais.

Se não existe ainda uma nacionalidade brasileira, se esta é uma construção ainda a ser feita, tal construção é vital ou, nas palavras do autor,

é de necessidade elementar para um povo jovem, que jamais chegará à idade da vida dinâmica, sem fazer-se "nação", isto é, sem formar a base estável, o arcabouço anatômico, o corpo estrutural da sociedade política (Torres, $1982^{a}$, p. 43).

O que Torres chama, enfim, de caráter nacional, nasce do reconhecimento da ignorância sobre o Brasil que tem, segundo ele, sido sempre a tônica das elites brasileiras, e que tem sido substituído por um repertório de idéias exóticas (Torres, 1982a, p. 53). Somente tal conhecimento tornará possível a superação da inconsciência mental na qual o país ainda vive, e do qual busca refugiar-se, apegando-se a um patriotismo oficial e litúrgico, o que o leva a concluir: "A substituição das imagens e dos símbolos, às realida- 
des, é sinal de enfraquecimento do espírito (Torres, 1982, p. 126)".

A construção deste conhecimento é pressuposto, ainda, para que uma ausência seja suprida: "a ausência de espírito nacional 'prático', da solidariedade patriótica fundada na consciência dos interesses comuns a todos os agrupamentos políticos, religiosos, econômicos, geográficos, comerciais e industriais (Torres, 1982a, p. 85)". Cabe aos intelectuais, então, construir o conhecimento que tornará possível a criação de uma unidade nacional até então ausente. A construção da nacionalidade brasileira é necessariamente artificial e deve partir da formação da consciência nacional (Torres, 1982a, p. 131). Seria a tarefa que o Estado Novo conclamaria os intelectuais de seu tempo a assumirem, atuando, bem entendido, sob a égide estatal. Também neste ponto, o pensamento de Torres antecipa aspectos básicos do autoritarismo, no caso, de sua política cultural.

Se o brasileiro possui qualidades positivas, ele é contudo, um povo degenerado, mas Torres acredita na viabilidade de sua regeneração. Segundo ele

Hoje, essa multidão de "forçados" da vagabundagem discípulos fidelíssimos da única escola e da única prática que se Ihes indicou e se Ihes expôs - está gravemente inveterada na indolência, profundamente abatida na reatividade do caráter e do espírito; não está, porém, degenerada (Torres, 1915, p. 35).

A regeneração do povo brasileiro é uma tarefa a ser levada a cabo pela elite. Mas de qual elite se trata? De uma elite de intelectuais, comprometida exatamente com esta tarefa; uma elite já existente, mas que necessita ser expandida e educada, e Torres, por sua vez, assume essa tarefa. Ele buscou discípulos e o fez conscientemente. Caberia a intelectuais e políticos comprometidos apenas com o bem nacional levarem adiante os seus projetos, e o que soa apenas como um chavão ganha, em sua obra, significado dos mais amplos. Ele define como função de uma elite de intelectuais a condução de um projeto de organização nacional em bases nacionalistas, 
corporativistas e autoritárias, e esses discípulos não deixariam de surgir nos próximos anos, assumindo, em maior ou menor grau, sua influência. A influência póstuma de Torres vai de encontro, assim, à necessidade, sempre acentuada por ele, de criar elites intelectuais dedicadas a um projeto de transformação nacional.

Ao mesmo tempo que cabe às elites intelectuais papel fundamental no projeto de Torres, ele próprio constata o desinteresse dessas elites em relação ao desempenho desse papel, ao afirmar: "Os intelectuais brasileiros consideram o preparo que possuem um meio de êxito pessoal, sem o ligar a nenhum dever, a nenhuma responsabilidade de ação e direção social (Torres, 1982, p. 91). E esta missão é tanto mais urgente, na medida em que toda nacionalidade é moldada à imagem e semelhança de suas elites: "Os povos tem sido moldados à imagem e semelhança de seus chefes, de seus padres e de seus sábios (Torres, 1982, p. 116)".

Toda política nacional deve partir "do estudo racional dos dados concretos da terra e da sociedade, observados e verificados pela experiência (Torres, 1982, p. 151)". E efetuar tal estudo é tarefa dos intelectuais.

O método de Torres toma tal estudo como base e, em carta escrita em 1916, ele acentua o caráter empírico de seu pensamento: "Dessa experiência e dessa observação, com elementos tirados do estudo da nossa terra e da nossa gente, resultou o programa que exponho em meus livros (Marson, 1989, p. 106)". E ressalta a necessidade de tal empirismo, em artigo publicado no mesmo ano: "Toda obra sensata, racional, prática, tem de partir da observação e da verificação dos fatos e das condições da nossa sociedade (Lima, 1935, p. 281)".

Ao fazer o elogio do autor, em 1917, Giberto Amado salienta precisamente o fato de este ter partido da observação dos fatos referentes à sociedade brasileira e não da adaptação de teorias estrangeiras (Amado, 1979, p. 199). De fato, os objetivos de Torres são estritamente pragmáticos, sendo ele um autor despido de pretensões teóricas. Como acentua Souza, "Alberto Torres não teve a pretensão de projetar categorias ou conceitos no- 
vos, uma obra ideológica ou filosófica, mas tão somente reorganizar a vida nacional com os dados disponíveis em nível sociológico - o fato social (Souza, 1999, p. 16)". E esta despretensão converte-se em virtude, perceptível, por exemplo, em seu estilo: Torres quase não cita, e demonstra solene despreocupação em exibir uma erudição que surge epidérmica e mal assimilada em tantos autores de seu tempo.

E não é apenas neste aspecto que sua obra é inovadora: com ele, novas explicações, não mais baseadas em pressupostos raciais dos quais ele foi crítico contumaz, passaram a ter livre curso na cultura brasileira. Autores até então tidos como canônicos, como Gobineau e Lapouge, foram contestados por ele a partir de uma relação entre racismo e poder por ele enfatizada (Carneiro, 1988, p. 93).

O povo brasileiro, para ele, não é inferior a nenhum outro e nem mais indolente; é apenas ignorante em relação à sua própria terra. Segundo Torres, "nós não sabemos ainda o que a nossa terra pode produzir e como deve produzir (Torres, 1982, p. 54)". A partir desta constatação, ele nega qualquer inferioridade racial ou identitária intrínseca ao brasileiro e produz, junto, aliás, com Manoel Bomfim, uma inovação decisiva na cultura brasileira.

Torres relativiza a influência da formação racial. Segundo ele, "a raça é, de todos os elementos da nacionalidade, talvez o menos ativo (Torres, 1982a, p. 54)". Menos ativo que outros fatores, já que "no conflito dos caracteres étnicos com os fatores mesológicos e sociais que operam sobre os diversos tipos humanos, a vitória cabe à última destas influências (Torres, 1982a, p. 30)".

Ele nega ainda a existência de qualquer desigualdade racial, salientando ter a doutrina que a defende perdido "todos os pontos de apoio em todas as regiões da ciência (Torres, 1982a, p. 62)”, definindo as raças como produtos do meio físico. Cada meio cria a raça mais apropriada para nele sobreviver e foi neste sentido - evolucionista, mas não racista - que ele 
explica a formação racial do brasileiro e suas virtudes, negando qualquer validade aos projetos de branqueamento tão comuns em sua época. Segundo Torres, "indígenas, africanos e seus descendentes formaram, em nosso território, tipos definitivos, admiravelmente apropriados às suas condições físicas, que só poderão, por isso, progredir e aperfeiçoar-se (Torres, 1982, p. 116)". Qualquer aperfeiçoamento artificial a ser feito é, portanto, inútil e insensato, e ele alerta: "A idéia de operar-se o aperfeiçoamento das nossas raças pelo cruzamento não tem base científica; a de substituir por outras, outrora e ainda hoje, já se apresenta com outro aspecto (Torres, 1982, p. 197)".

A degeneração racial do brasileiro - tema comum a autores de seu tempo - é recusada por Torres como "o hábito de menoscabar do nosso sangue, de depreciar a nossa idoneidade física e moral, de nos dar por um povo degenerado, corrompido, em franco estado de abatimento corpóreo e moral (Torres, 1982a, p. 79)". Ele reage a esta concepção e acentua que os fatores que levam a tal abatimento são de ordem social - pouca ou nenhuma instrução, alimentação escassa, péssimas condições de saúde e higiene, moradias inadequadas - e não racial. Inverte, portanto, a escala de fatores ainda predominante no pensamento brasileiro e abre caminho há uma análise, acima de tudo, social da realidade brasileira.

E o otimismo de fundo milenarista que é uma constante em sua obra transparece, também, quando ele analisa a questão da miscigenação, com o Brasil surgindo como uma espécie de terra prometida:

Por sua extensão, seus climas variados e suas diferentes zonas de cultura, o Brasil dir-se-ia feito para reunir e abrigar povos de origens e raças diferentes. Nenhum outro país pode, talvez, em iguais condições, realizar o tipo de sociedade política cosmopolita, que é o fim natural das nações novas (Torres, 1982, p. 130).

O nacionalismo de Torres liberta-se, enfim, do pessimismo calcado em teorias raciais de seus antecessores, e ele e Manoel Bomfim, ao aban- 
donarem tais teorias, como acentua Dante Moreira Leite, "foram capazes de compreender que o atraso do Brasil não se devia a condições psicológicas imutáveis, mas a condições históricas e econômicas que os homens podiam superar (Leite, 1976, p. 259)".

Se o pensamento de Torres é inovador em termos teóricos e metodológicos, é conservador em termos sociais. A obra do autor pode ser definida como uma tentativa de reação ao processo - ainda precário, mas já em desenvolvimento - de urbanização e industrialização pelo qual passava a sociedade brasileira de seu tempo. Às crises e diferenciações sociais advindas de tal processo, à ruptura de valores e tradições que ele acarreta, à competitividade e individualismo que o caracteriza, Torres propõe a constituição de um núcleo estatal capaz de conferir homogeneidade a uma sociedade em processo de diversificação e potencial desintegração.

Seria um projeto apenas reacionário, caso Torres se limitasse a condenar o processo de mudança social por ele analisado, mas ele vai além e busca adaptar-se a ele: busca direcioná-lo. Torres reconhece a inevitabilidade das mudanças sociais, mas teme que elas adquiram um sentido de ruptura. Como salienta Simões, "Torres não propõe a modificação completa de toda a sociedade. Propõe modificações, apenas (Simões, 1981, p. 180)" aqui, ele se coloca no pólo oposto ao ocupado por Bomfim, defensor de uma mudança revolucionária.

Em 1893, quando deputado estadual, Torres defende a mudança da capital de seu estado, uma vez que "a 'ação plutocrática do centro comercial do Rio de Janeiro' ameaçava limitar a autonomia política de Niterói (Marson, 1989, p. 56)". Nesta fase de sua trajetória já surge, então, o ideal de uma política desvinculada de interesses econômicos e alheia a pressões do capitalismo. Uma política, em síntese, estruturada a partir da conciliação e, não, da dominação.

A urbanização brasileira é vista por Torres como um processo anômalo, na medida em que levaria à dissolução dos valores nucleares da socieda- 
de brasileira (Martins, 1975, p. 3). E um processo postiço: o brasileiro construiu edifícios modernos, implantou no país um simulacro de modernidade. Simulacro precisamente porque o "espírito brasileiro mantém-se alheio a ela". Segundo Torres, "o espírito brasileiro é ainda um espírito romântico e contemplativo, ingênuo e simples, em meio de seus palácios e de suas avenidas, de suas bibliotecas e de seus mostruários de elegâncias e de vastos idealismos (Torres, 1982a, p. 14)".

A cidade e o campo são vistas por Torres a partir de uma rígida dualidade. No campo, impera o trabalho produtivo e organizado, herança da escravidão, o que o leva a fazer o elogio das conseqüências do sistema escravista. Segundo ele, "social e economicamente, a escravidão deu-nos, por longos anos, todo o esforço e toda a ordem que então possuímos, e fundou toda a produção material que ainda temos (Torres, 1982a, p. 32)". Ela foi o alicerce da formação nacional, e é sua herança que permanece servindo de base para o que o Brasil possui de organização nacional, em contraponto à desestruturação provocada pela influência urbana.

Torres faz, portanto, o elogio, senão da escravidão, pelo menos de seus efeitos - a criação das bases da organização nacional. Já a abolição é criticada por seu caráter exclusivamente humanitário e sentimental e pelas suas conseqüências, já que "a abolição fez-se e a lavoura ficou desorganizada (Torres, 1982, p. 58)". Os abolicionistas foram impulsionados pelo interesse sentimental pelo negro, mas a abolição não foi seguida pela preocupação em integrar o negro à sociedade, deixando-o à margem e preferindo a importação de imigrantes (Torres, 1982, p. 161).

O desenvolvimento, para Torres, passa, não pela industrialização e urbanização, mas sim pela exploração sistemática e racional dos recursos agrícolas, bem como pela preservação dos recursos naturais, o que o leva a desenvolver uma consciência ecológica consideravelmente aguçada para o período histórico no qual viveu.

Mas para que tal objetivo tivesse sido alcançado, entretanto, teria sido preciso adaptar o brasileiro ao meio em que vive, por ser este um meio 
novo e estranho ao europeu. Nada disso, contudo foi feito, e o resultado histórico foi a criação e consolidação de um comportamento predatório. Segundo Torres,

O colono e o comerciante localizados no Brasil, seus descendentes e seus discípulos, ficaram sendo seres, assim, estranhos a seu habitat, eternos desaclimados exploradores vorazes, a princípio, de seus bens, vítimas, afinal, de novos exploradores (Torres, 1982, p. 96).

E, por serem estranhos, eles agiram como predadores:

A exploração colonial dos povos sul-americanos foi um assalto às suas riquezas; toda a sua história econômica é o prolongamento deste assalto, sem precauções conservadoras, sem corretivos reparadores, sem piedade para com o futuro, sem atenção para com os direitos dos pósteros (Torres, 1982a, p. 96).

Torres guarda profunda desconfiança em relação ao capitalismo. É um autor conservador, na medida em que busca resguardar a influência da tradição do domínio do que chama de hierarquia argentária. Segundo ele, "o argentarismo, embora alheio à política, domina mais que os próprios poderes públicos e irrita a chaga da miséria (Torres, 1982, p. 127)". Cabe ao Estado, então, sobrepor-se ao poder desta hierarquia e fazer predominar os verdadeiros interesses nacionais, ao invés de deixar-se dominar por interesses que ele considera alheios à nação. Seu nacionalismo, portanto, é nitidamente anticapitalista, daí ter sido ele elevado à condição de ícone também por autores ligados à esquerda, como Nelson Werneck Sodré.

A atração de capitais externos tende a favorecer apenas uma pequena elite, a fortalecer o processo de urbanização e a promover a migração do habitante do interior para a cidade e, ainda, a aprofundar o abandono em que se encontra o interior (Torres, 1982, p. 55). Gera conseqüências, portanto, que negam todos os princípios do autor; contrariam frontalmente seu 
arraigado agrarismo.

E o agrarismo é a pedra angular de seu pensamento e de seu projeto para a nação. O Brasil deve ser, segundo ele, em primeiro lugar um país agrícola, sendo ridículo contestar-lhe este destino, diante de seu vasto território. Deve manter, depois, o cultivo dos produtos necessários à vida e dos que empregam matéria-prima nacional (Torres, 1982, p. 207).

E qual a importância de Torres para a afirmação do nacionalismo no Brasil? Segundo Fiori

O nacionalismo afirmou-se no Brasil como um discurso crítico à ordem liberal através dos "publicistas" que, a partir da obra germinal de Alberto torres sobre a organização nacional (1914), conseguem introduzir na agenda política a idéia de nação associada ao progresso econômico e à centralização estatal ( Fiori, 1994, p. 135).

Conservadorismo, agrarismo e nacionalismo caminham juntos em sua obra: são indissociáveis. Assim como seu nacionalismo, o agrarismo de Torres é essencialmente anticapitalista. Sua sociedade ideal - utópica, diria Lamounier - é "uma sociedade concorrencial fechada na qual a existência da pequena empresa é assegurada, e estimulada a competição entre os produtores (Lamounier, 1983, p. 360)".

O nacionalismo de Torres é radical, não conhece meias medidas. Como acentua Luz, "para ele todas as atividades econômicas exercidas por estrangeiros eram nocivas ao país, porque todas estavam destruindo as 'fontes vitais' do país em troca de futilidades, de gêneros supérfluos (Luz, 1975, p. 98)".

E seu nacionalismo não foi, finalmente, apenas de cunho teórico, ganhou expressão prática quando ele e Alberto de Faria iniciaram, em 1912, uma campanha contra o "império" de Percival Farquar, dono de várias ferrovias no Brasil e de diversas propriedades rurais, entre elas a que hoje cons- 
titui o estado do Amapá.

A adoção de uma política nacionalista é, para Torres, questão de sobrevivência nacional. Segundo ele, "a política de um povo moderno, para a paz ou para a guerra, consiste na arte de conservar, de obter e de aumentar riquezas. Tal é a política ofensiva de outros povos, tal precisa ser a nossa política defensiva (Torres, 1982a, p. 91)". O nacionalismo seria, então, instrumento de defesa das riquezas nacionais: questão de segurança nacional, para usarmos uma expressão alheia a seu tempo. Mas não é o que ocorre, e ele ironiza, ao presenciar o que considera a devastação das riquezas naturais brasileiras: "Para os nossos estadistas, esse ataque às reservas da nossa natureza, por sindicatos estrangeiros - que apenas usam, do nosso país, quando não as trazem, as máquinas estrangeiras - representam auspiciosas 'colocações de capitais' (Torres, 1982a, p. 92)".

Torres indica, por conseguinte, a existência de dois caminhos a serem percorridos: a consolidação da independência social e econômica a partir da preservação do que ele chama de órgãos vitais da nacionalidade, ou a transformação do país em uma colônia tropical de companhias e sindicatos estrangeiros (Torres, 1982a, p. 107).

A opção a ser feita é entre nacionalismo e alienação. Torres retoma o conceito de alienação e o transforma em eixo de seu nacionalismo. Uma nação alienada é uma nação que ainda não tomou consciência de seus reais interesses e, por isto, permanece ainda - mesmo que seja formalmente independente - na condição de colônia. Elites desligadas da realidade nacional, alheias aos problemas nacionais e despreocupadas no que tange a seu estudo, são elites alienadas.

Traçando tais alternativas e definindo a defesa das riquezas nacionais como condição para a criação de uma nação soberana, Torres transformou sua obra em ponto de partida para a criação de um ideário nacionalista - e não cabe, aqui, questionar seu anacronismo ou sua relevância para os dias atuais - que atravessaria todo o século e estaria no centro de inúmeras 
campanhas e debates. Fazendo isso, ele se transformou em autor fundamental no pensamento brasileiro.

Retomo, finalmente, as questões inicialmente colocadas e concluo a partir delas: a adoção de uma política liberal inviabilizaria a adoção, pelo Estado, do papel que cabe a ele exercer, que é o de construir as bases da nacionalidade. E o nacionalismo permitiria às elites brasileiras firmarem um compromisso com a nacionalidade que até então, segundo ele, mal foi esboçado. Definindo estes dois caminhos - um autoritário, outro nacionalista - e conjugando-os, Torres disseminou sua influência.

\section{Referências}

AMADO, Gilberto. Perfis parlamentares. Brasília: Câmara dos Deputados, 1979.

ATHAYDE, Tristão de. Política. Rio de Janeiro: Editora Livraria Católica, 1932.

CARNEIRO, Maria Luiza Tucci. O anti-semitismo na era Vargas (1930-1945). São Paulo: Brasiliense, 1988.

COSTA, Valeriano Mendes Ferreira. Vertentes democráticas em Gilberto Freyre e Sérgio Buarque. Lua Nova, São Paulo, n. 26, CEDEC, 1992.

FAUSTO, Boris. A revolução de 1930: historiografia e história. São Paulo: Brasiliense, 1970.

FELIX, Loiva Otero. Alberto Torres: o político militante. Revista do Instituto de Filosofia e Ciências Humanas da UFRGS, Porto Alegre, ano IV. 1976.

FERNANDES, Florestan. Mudanças sociais no Brasil. São Paulo: DIFEL, 1979.

FIORI, José Luiz. O nó cego do desenvolvimentismo brasileiro. In: Novos Estudos CEBRAP. São Paulo: CEBRAP, 1994. 
Sociologias, Porto Alegre, ano 7, no 13, jan/jun 2005, p. 302-323

LAMOUNIER, Bolivar. Formação de um pensamento autoritário na Primeira República. In: FAUSTO, Boris. História geral da civilização Brasileira. Tomo III. Vol. II. São Paulo: DIFEL, 1983.

LEITE, Dante Moreira. O caráter nacional brasileiro: história de uma ideologia. São Paulo: Nacional, 1976.

LIMA, A. Sabóia. Alberto Torres e sua obra. São Paulo: Nacional, 1935.

LINS, Álvaro. Rio Branco. São Paulo: Nacional, 1965.

LUZ, Nícia Vilela. A década de 1920 e suas crises. Revista do Instituto de Estudos Brasileiros, São Paulo, n. 6, USP, 1969.

. A luta pela industrialização no Brasil. São Paulo: Alfa-Ômega, 1975.

MARSON, Adalberto. A ideologia nacionalista de Alberto Torres. São Paulo: Duas Cidades, 1979.

MARTINS, José de Souza. Capitalismo e tradicionalismo. São Paulo: Pioneira, 1975.

MELO, Marcus André B. C. de. Municipalismo, nation-building e a modernização do Estado no Brasil.Revista Brasileira de Ciências Sociais, São Paulo, n. 23, ANPOCS, 1993.

MONZANI, Luiz Roberto. Símbolos e bandeiras. In: NOVAES, Adauto (Org.). A crise da razão. São Paulo: Companhia das Letras, 1999.

NOGUEIRA, José Antônio. O ideal brasileiro desenvolvido na república. In: CARDOSO, Vicente Licínio (Org.). À margem da história da República. Recife: Fundação Joaquim Nabuco/Editora Massangana, 1990.

RAMOS, Guerreiro. Introdução crítica à sociologia brasileira. Rio de Janeiro: Andes, 1957.

. A crise do poder no Brasil (problemas da revolução social brasileira). Rio de Janeiro: Zahar, 1961.

SALDANHA, Nelson. Rui Barbosa e o bacharelismo liberal. In: CRIPPA, Adolpho 
(Org.). Idéias políticas no Brasil. São Paulo: Convívio, 1979.

SIMÕES. Teotônio. Repensando Alberto Torres. São Paulo: Semente, 1981.

SOUZA, Francisco Martins de. Raízes teóricas do corporativismo brasileiro. Rio de Janeiro: Tempo Brasileiro, 1999.

TAVARES, José Nilo. Autoritarismo e dependência: Oliveira Vianna e Alberto Torres. Rio de Janeiro: Achiamé, 1979.

Recebido: 10/05/2004

Revisão: 16/06/2004

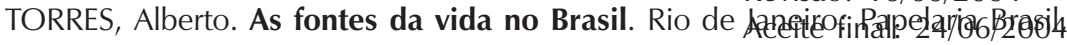
1915.

. A formação brasileira e o desenvolvimento da economia nacional. Cultura Política, Rio de Janeiro, n. 7, 1941.

. O problema nacional brasileiro. Brasília: Editora da UnB, 1982.

. A organização nacional. Brasília: Editora da UnB, 1982a.

VIANNA, Luis Werneck. Liberalismo e sindicato no Brasil. Rio de Janeiro: Paz e Terra, 1978.

VIEIRA, Evaldo. Autoritarismo e corporativismo no Brasil. São Paulo: Cortez, 1981.

\section{Resumo}

O texto analisa a obra de Alberto Torres, enfatizando seus eixos principais: autoritarismo e nacionalismo. Ressalta o caráter inovador desta obra, ao questionar as teorias raciais então vigentes na cultura brasileira e ao enfatizar a necessidade de tomar como ponto de partida o estudo empírico da realidade brasileira. E estuda o impacto de suas idéias, bem como sua importância para a criação de um pensamento autoritário brasileiro, bem como para a construção de um ideário nacionalista.

Palavras-Chave: Autoritarismo, Nacionalismo, Modernidade. 


\section{Nationalism and authoritarianism in Alberto Torres}

\section{Ricardo Luiz de Souza}

The text examines Alberto Torres' work, stressing its core themes: authoritarianism and nationalism. It emphasizes the innovative character of the work when it questions racial theories then present in Brazilian culture and stressing the need to take as starting point the empirical study of Brazilian reality. It also studies the impact of the author's ideas as well as their importance for the creation of a Brazilian authoritarian thinking and the construction of nationalist ideas.

Key words: Authoritarianism, Nationalism, Modernity. 